\title{
Prescription opioid overdose and adverse effect hospitalisations among injured workers in eight states (2010-2014)
}

\author{
Jeanne M Sears ๑1 ,1,2 Sheilah Hogg-Johnson, 2,3 Ryan A Sterling, ${ }^{4}$ \\ Deborah Fulton-Kehoe, ${ }^{4}$ Gary M Franklin ${ }^{4,5}$
}

- Additional material is published online only. To view, please visit the journal online (http://dx.doi.org/10.1136/ oemed-2020-106472).

${ }^{1}$ Department of Health Services, University of Washington, Seattle, Washington, USA ${ }^{2}$ Institute for Work and Health, Toronto, Ontario, Canada ${ }^{3}$ Canadian Memorial Chiropractic College, Toronto, Ontario, Canada ${ }^{4}$ Department of Environmental and Occupational Health Sciences, University of Washington, Seattle, Washington, USA ${ }^{5}$ Washington Department of Labor and Industries, Tumwater, Washington, USA

\section{Correspondence to}

Dr Jeanne M Sears, Department of Health Services, University of Washington, Seattle, WA 98195 USA; jeannes@uw.edu

Received 9 February 2020 Revised 21 March 2020 Accepted 24 March 2020

Published Online First 10 April 2020

\section{ABSTRACT \\ Objective High-risk opioid prescribing practices in} workers' compensation (WC) settings are associated with excess opioid-related morbidity, longer work disability and higher costs. This study characterises the burden of prescription opioid-related hospitalisations among injured workers.

Methods Hospital discharge data for eight states (Arizona, Colorado, Michigan, New Jersey, New York, South Carolina, Utah and Washington) were obtained from the State Inpatient Databases, Healthcare Cost and Utilization Project, Agency for Healthcare Research and Quality. We calculated 5-year (2010-2014) average annual rates of prescription opioid overdose/adverse effect (AE) hospitalisations. Injured workers were identified using payer (WC) and external cause codes. Results State-level average annual prescription opioid overdose/AE hospitalisation rates ranged from 0.3 to 1.2 per 100000 employed workers. Rates for workers aged $\geq 65$ years old were two to six times the overall rates. Among those hospitalised with prescription opioid overdose/AEs, injured workers were more likely than other inpatients to have a low back disorder diagnosis, and less likely to have an opioid dependence/abuse or cancer diagnosis, or a fatal outcome. Averaged across states, WC was the primary expected payer for $<1 \%$ of prescription opioid overdose/AE hospitalisations vs $6 \%$ of injury hospitalisations.

Conclusions Population-based estimates of prescription opioid morbidity are almost nonexistent for injured workers; this study begins to fill that gap. Rates for injured workers increased markedly with age but were low relative to inpatients overall. Research is needed to assess whether WC as payer adequately identifies work-related opioid morbidity for surveillance purposes, and to further quantify the burden of prescription opioid-related morbidity.

\section{INTRODUCTION}

The burden of occupational injuries and illnesses on workers and society extends beyond incidence and short-term impact to include downstream health outcomes, disability and costs. ${ }^{12}$ Estimated total annual medical and indirect costs of occupational injuries and illnesses in the USA are a staggering $\$ 250$ billion, competing with total costs of cancer. ${ }^{1}$ Suboptimal healthcare practices contribute to the preventable burden of occupational injuries and illnesses. ${ }^{34}$ It is well-documented that opioid
Key messages

What is already known about this subject?

- High-risk opioid prescribing practices in workers' compensation (WC) settings are associated with excess opioid-related morbidity longer work disability and higher WC costs.

- Accurate surveillance of opioid morbidity rates and demographic patterns is necessary for effective prevention planning, intervention and evaluation, but population-based estimates of opioid-related morbidity among injured workers are almost non-existent.

What are the new findings?

- Observed rates of prescription opioid overdose/ adverse effect (AE) hospitalisations were relatively low for injured workers, in the neighborhood of 1 per 100000 employed workers. We describe several important barriers to accurate opioid morbidity surveillance among injured workers.

- Rates for injured workers ages 65 years and older were two to six times the overall rates.

How might this impact on policy or clinical practice in the foreseeable future?

- Our findings regarding significantly higher rates of prescription opioid overdose/AE hospitalisations among older injured workers warrant close attention, and suggest that clinicians prescribing opioids to older workers should carefully assess potential risk related to physiological changes associated with ageing, as well as presence of chronic conditions, social and mental health factors, and other prescription medications.

prescribing practices over the past two decades have contributed to a national epidemic of opioid overdose hospitalisations and deaths. ${ }^{5-7}$

Injured workers are frequently exposed to highrisk opioid prescribing practices. ${ }^{89}$ These practices have been associated with excess opioid-related morbidity/mortality, longer work disability and higher workers' compensation (WC) costs. ${ }^{5}{ }^{10-12} \mathrm{~A}$ systematic review found that the mean opioid dose prescribed in WC settings was higher than that in non-WC settings. ${ }^{8}$ 
Prescription opioids have been studied as both a risk factor for and a consequence of work-related injuries. ${ }^{13}$ In the National Employer Survey, 8\% of employers reported experiencing a prescription opioid-related workplace overdose incident ${ }^{14}$; however, overdose related to treatment of work injuries may occur at work or elsewhere. Though overdose and adverse effects (AEs) from opioid pain medications prescribed for occupational injuries may be covered by WC, courts have variably ruled in cases involving an independent intervening act breaking the chain of causation from injury to overdose (eg, opioids inappropriately prescribed or not taken as prescribed). ${ }^{15}$ Potential work-related scenarios include prescription opioid overdose/AE: (1) from opioids prescribed for a work injury or ensuing surgery; (2) from non-medical use of prescription opioids, subsequent to opioid prescribing for a work injury; (3) during WC-covered opioid use disorder treatment; (4) causing or concurrent with a work injury incident; or (5) during inpatient treatment/surgery for a work injury. Regardless of the specific scenario, prescription opioid-related morbidity among injured workers constitutes an unacceptable, preventable and largely iatrogenic burden on WC, workers and society overall.

There are significant knowledge gaps regarding prevalence of opioid-related morbidity among injured workers, in part due to the difficulty of identifying work-related events in many population-based data sets. Most states do not have a population-based WC system, inhibiting the use of state WC data to assess the burden of opioid-related morbidity on workers or to compare findings across states. In 2005, Franklin et $a l^{9}$ first identified the emerging opioid epidemic using WC data from Washington, one of only four states with an exclusive state fund and no private WC insurers.

Few population-based estimates of opioid-related morbidity/ mortality rates among workers exist. Washington state researchers used WC data to calculate annual rates (2004-2010) of prescription opioid poisonings among workers with opioid prescriptions paid for by WC (roughly 3-5 per 10000 ) and AE (roughly 9-15 per 10000$).{ }^{11}$ We were unable to identify other rate estimates specific to overdose resulting from prescription opioids taken consequent to work injury/illness. However, one study estimated the annual fatal drug overdose rate (not limited to opioids) in US workplaces as 0.09 per 100000 full-time equivalents (FTE) between 2011 and 2016. ${ }^{16}$ In another study, the 5-year average annual fatal opioid overdose rate among Massachusetts workers was estimated at 25.1 deaths per 100000 workers (not restricted to employed workers or to workplace fatalities), based on death certificates. ${ }^{17}$ Long-term accidental poisoning mortality for West Virginia injured workers with low back pain was significantly higher than that for the general population (SMR: 1.62); 92\% of these deaths involved opioid overdose. ${ }^{18}$ Long-term drug-related mortality hazard was two to three times higher for New Mexico injured workers compensated for over 7 days of lost work, compared with workers receiving only medical benefits. ${ }^{19}$ The latter two studies assessed the general risk of work injury and associated disability on long-term opioid-related mortality (up to 17.0 and 19.5 years after injury, respectively), but did not assess risk related to opioids prescribed for the work injury.

Improving surveillance of opioid morbidity rates and demographic patterns is necessary for effective prevention planning, intervention and evaluation. The aim of this study was to describe and quantify the burden of inpatient hospitalisations involving opioid-related overdose (poisoning) and AE among injured workers, including (1) demographics of workers hospitalised with opioid-related overdose/AE; (2) frequency of opioidrelated inpatient deaths and other relevant diagnoses among hospitalised injured workers, compared with other inpatients; and (3) population-based rates of hospitalisations for opioid overdose/AE among injured workers. We also discuss methodological challenges related to case definitions, case ascertainment and small numbers.

\section{METHODS}

\section{Data source and study population}

Eight distinct population-based state hospital discharge databases were used for this study. Hospital discharge data for Arizona, Colorado, Michigan, New Jersey, New York, South Carolina, Utah and Washington state were obtained from the State Inpatient Databases (SID), Healthcare Cost and Utilization Project (HCUP). ${ }^{20}$ These states represented diverse geographical areas and satisfied selection criteria including presence of a payer category specific to WC and consistent usage of International Classification of Diseases, Ninth Revision, Clinical Modification (ICD-9-CM) external cause of injury codes (E-codes). The 2010-2014 time frame was selected for two reasons: (1) new ICD-9-CM E-codes indicating work relatedness were first introduced on 1 October 2009 (E000) ${ }^{21}$ and (2) the ICD-10-CM lexicon took effect on 1 October 2015. Hospital discharges for state residents aged 15 years and over were included. Hospital discharges for persons aged 65 years and older were excluded from primary payer percentage calculations and from comparisons between injured workers and the general inpatient population. In a previous work with SID, those aged 65 years and older comprised under $10 \%$ of occupational injury hospitalisations but roughly half of the non-occupational injury hospitalisations. ${ }^{22} 23$

\section{Data definitions}

We used ICD-9-CM diagnoses and E-codes to define four categories of opioid morbidity (see online supplementary table 1 for codes): (1) prescription opioid overdose, (2) prescription opioid AE, (3) heroin overdose and (4) heroin AE. Prescription opioids were defined as all opioids other than heroin, including methadone. The ICD-9-CM lexicon does not differentiate synthetic opioids nor does it identify whether the opioids were obtained via prescription. ICD-9-CM coding guidance defines drug poisoning as resulting from errors made in drug prescribing or administration, including the wrong substance or dose, and defines $\mathrm{AE}$ as resulting from correct prescribing and proper administration of the correct drug. ${ }^{21}$ An overdose resulting from a correctly prescribed/administered dose might be classified as either overdose or AE. ${ }^{11}$ Overdose counts were too low to present overdose and $\mathrm{AE}$ rates separately.

All listed diagnoses and E-codes were used to identify opioid overdose/AE, the most sensitive approach. ${ }^{24}$ We used all available data fields (diagnoses: 9-30, E-codes: 6-16).

Injured workers were defined in two ways. First, persons whose hospital discharges had WC listed as primary expected payer were presumed to be injured workers. The Council of State and Territorial Epidemiologists (CSTE) uses WC as primary payer as a proxy for work relatedness of hospitalised injuries, ${ }^{25}$ which has been estimated to be $89 \%$ sensitive and $98 \%$ specific. ${ }^{26}$ Second, we expanded that definition by including hospitalisations with all-listed E-codes that specifically identified work as the external cause of the hospitalisation (see online supplementary table 1 for codes). ${ }^{26}$

Several other data definitions were based on ICD-9-CM diagnosis and/or E-codes (see online supplementary table 1 for specific codes). The definition of opioid dependence or abuse included alllisted diagnoses for opioid dependence (alone or in combination 
with other drugs) or non-dependent opioid abuse. The definition of cancer-of interest because taking opioids for cancer-related pain might escalate opioid-related morbidity-included all-listed cancer diagnoses, excluding non-melanoma skin cancer. Injury hospitalisations were defined as any first-listed diagnosis contained in the injury section within the Injury and Poisoning chapter of the ICD-9-CM lexicon. Low back disorder was based on all-listed diagnoses and defined as specified for the CSTE Occupational Heath Indicator \#20 (per table 1, page 123, in the indicator guide; table 3 exclusions were not applied). ${ }^{25}$

Race/ethnicity was based on the HCUP uniform data element, which contains mutually exclusive race and ethnicity categories within one data element (race). When constructing the uniform data element from separate race and ethnicity data fields in state source data, HCUP gave ethnicity precedence over race. For this study, several race/ethnicity categories were collapsed because counts were too low to meet HCUP reporting requirements.

\section{Rates and denominators}

For each of the eight included states-for injured workers and for all inpatients-we calculated 5-year average annual rates of prescription opioid overdose/AE hospitalisations, along with Poisson exact 95\% CIs. We also calculated age-specific and gender-specific rates where there were adequate counts. Counts were generally too low to support direct standardisation. However, in previous occupational injury studies based on the SID, we found only slight and unremarkable differences between crude and age-adjusted estimates. ${ }^{22} 23$ Employed worker denominators used to calculate rates for injured workers were based on the Bureau of Labour Statistics' Current Population Survey, using the Employed Labor Force query system. ${ }^{27}$ Civilian population denominators used to calculate rates for all inpatients were based on US Census Bureau annual estimates. ${ }^{28}$

\section{Data analysis}

The percentage of hospital discharges with WC listed as primary expected payer was calculated for the prescription opioid overdose/AE hospitalisation subset, and-for comparison purposesfor several other diagnostic subsets. Among persons aged 15-64 years who were hospitalised with prescription opioid overdose/ $\mathrm{AE}$, we compared injured workers to other inpatients regarding prevalence of several diagnostic categories, averaging across the eight states due to small numbers. Among workers hospitalised with prescription opioid overdose/AE, we used descriptive statistics to summarise demographic characteristics, associated discharge diagnoses and inpatient deaths. In accordance with HCUP data use requirements, data were not reported for table cells containing fewer than 11 hospital discharges or when reporting would enable calculation of adjacent small cell sizes. Statistical tests were two-tailed, with statistical significance defined as $\mathrm{p} \leq 0.05$. Analyses were conducted using Stata/MP V.15.1 for Windows. ${ }^{29}$

\section{RESULTS}

Among inpatients aged 15-64 years (not restricted to injured workers), WC was the primary expected payer for less than $1 \%$ of prescription opioid overdose/AE hospitalisations, averaged across eight states $(0.22 \%$ of overdose hospitalisations and $1.27 \%$ of AE hospitalisations). In contrast, WC was listed as the primary expected payer for roughly $6 \%$ of injury hospitalisations and roughly $5 \%$ of hospitalisations with a low back disorder diagnosis (table 1). Among injured workers 15 years and older who were identified using only E-codes, WC was the primary expected payer for about two-thirds (67.43\%) of hospitalisations for any diagnosis and for $59.42 \%$ when restricted to prescription opioid overdose/AE hospitalisations, averaged across all eight states.

The prevalence of an opioid dependence/abuse diagnosis among injured workers hospitalised with prescription opioid overdose/AE was $6.10 \%$, compared with $19.43 \%$ for other inpatients with prescription opioid overdose/AE $(p<0.0005)$. The prevalence of a low back disorder diagnosis among injured workers hospitalised with prescription opioid overdose/AE was $29.34 \%$, compared with $8.97 \%$ for other inpatients with prescription opioid overdose/AE $(\mathrm{p}<0.0005)$. The prevalence of a cancer diagnosis among injured workers hospitalised with prescription opioid overdose/AE was $<1 \%(\mathrm{n}<11)$, compared with $9.11 \%$ for other inpatients with prescription opioid overdose/AE $(\mathrm{p}<0.0005)$. The percentage of inpatient deaths among injured workers hospitalised with prescription opioid overdose/ $\mathrm{AE}$ was $<1 \%$, compared with $1.86 \%$ for other inpatients with prescription opioid overdose/AE $(\mathrm{p}=0.001)$.

Counts of prescription overdose/AE hospitalisations among injured workers are presented in table 2. On average, there were about six times as many AE hospitalisations as overdose hospitalisations. Prescription opioid overdose/AE case capture increased by about 3\% when using injured worker E-codes, in addition to $\mathrm{WC}$ as payer. First-listed diagnoses/E-codes captured about $60 \%$ of the prescription overdose/AE cases captured when using all-listed diagnoses/E-codes. Small numbers posed a challenge; $50 \%$ of states did not have enough prescription opioid overdose hospitalisations to enable reporting overdose separately from AE. There were fewer than 11 heroin overdose hospitalisations and no heroin AE hospitalisations identified among injured workers across all eight states and all 5 years.

Averaged across eight states, $5.65 \%$ of injured workers with prescription opioid overdose/AE were black/African-American;

Table 1 Percentage of hospitalisations with WC listed as primary expected payer by diagnosis subset and state (among inpatients aged 15-64 years, not restricted to injured workers)

\begin{tabular}{|c|c|c|c|c|c|c|c|c|c|}
\hline \multirow[b]{2}{*}{ Diagnosis subset } & \multicolumn{9}{|c|}{ Percentage of hospitalisations with WC listed as primary expected payer } \\
\hline & $A Z$ & $\mathrm{CO}$ & MI & NJ & NY & SC & UT & WA & 8 states* \\
\hline Prescription opioid overdose/adverse effect & 0.58 & 0.86 & 0.37 & 0.62 & 1.10 & 0.40 & 0.47 & 1.13 & 0.75 \\
\hline Opioid dependence/abuse diagnosis & 0.55 & 0.60 & 0.43 & 0.74 & 0.55 & NR & NR & 1.48 & 0.66 \\
\hline Cancer diagnosis & NR & NR & 0.50 & 0.95 & 1.03 & NR & NR & 0.58 & 0.71 \\
\hline Low back disorder diagnosis & 3.37 & 4.14 & 3.11 & 5.72 & 6.83 & 2.77 & 4.31 & 5.04 & 4.67 \\
\hline Injury hospitalisation & 4.98 & 6.15 & 4.90 & 6.64 & 6.67 & 4.54 & 7.33 & 8.45 & 6.16 \\
\hline
\end{tabular}

*Percentages in the eight-states column were averaged across all eight states, including cells not separately reported.

AZ, Arizona; CO, Colorado; MI, Michigan; NJ, New Jersey; NR, not reported due to small cell size ( $\leq 10)$, in accordance with HCUP guidance; NY, New York; SC, South Carolina; UT, Utah; WA, Washington; WC, workers' compensation. 
Table 2 Counts of prescription opioid overdose and AE hospitalisations among injured workers by event type, injured worker definition* and state (2010-2014)

\begin{tabular}{|c|c|c|c|c|c|c|c|c|c|}
\hline \multirow[b]{2}{*}{ Prescription opioid event and worker definition } & \multicolumn{9}{|c|}{ Hospitalisation counts (2010-2014) } \\
\hline & $A Z$ & $\mathrm{CO}$ & MI & NJ & NY & SC & UT & WA & 8 states $\dagger$ \\
\hline \multicolumn{10}{|l|}{ Overdose, all-listed } \\
\hline Injured worker definition: payer only & 14 & NR & 11 & NR & 49 & NR & NR & 36 & 138 \\
\hline Injured worker definition: payer+E-codes & 16 & NR & 11 & NR & 49 & NR & NR & 37 & 142 \\
\hline \multicolumn{10}{|l|}{$A E$, all-listed } \\
\hline Injured worker definition: payer only & 110 & NR & 73 & NR & 290 & NR & NR & 144 & 835 \\
\hline Injured worker definition: payer+E-codes & 117 & NR & 73 & NR & 291 & NR & NR & 149 & 859 \\
\hline \multicolumn{10}{|l|}{ Overdose or $\mathrm{AE}$, all-listed $\ddagger$} \\
\hline Injured worker definition: payer only & 124 & 104 & 83 & 81 & 339 & 31 & 30 & 180 & 972 \\
\hline Injured worker definition: payer+E-codes & 133 & 110 & 83 & 85 & 340 & 31 & 32 & 186 & 1000 \\
\hline \multicolumn{10}{|l|}{ Overdose or $\mathrm{AE}$, first-listed } \\
\hline Injured worker definition: payer only & 54 & 61 & 51 & 64 & 192 & 27 & 15 & 130 & 594 \\
\hline Injured worker definition: payer+E-codes & 56 & 64 & 51 & 64 & 192 & 27 & 15 & 131 & 600 \\
\hline
\end{tabular}

${ }^{*}$ Two injured worker definitions are used in this table: (1) payer only and (2) payer along with ICD-9-CM E-codes. Details are presented in online supplementary table 1.

†Totals in the eight-states column were summed across all eight states, including cells not separately reported.

¥In some cases, all-listed overdose and all-listed AEs sum to less than all-listed overdose or AEs because a few hospital discharge records were counted in both categories,

AE, adverse effect; AZ, Arizona; CO, Colorado; E-codes, ICD-9-CM external cause of injury codes; ICD-9-CM, International Classification of Diseases, Ninth Revision, Clinical Modification; MI, Michigan; NJ, New Jersey; NR, not reported due to small cell size ( $\leq 10)$, in accordance with HCUP guidance; NY, New York; SC, South Carolina; UT, Utah; WA,

Washington State; WC, workers' compensation.

$1.17 \%$ were Asian/Pacific Islander; and $<1 \%$ were Native American (due to small numbers, these categories were included within other/multiple in table 3). Averaged across states, $2.70 \%$ were aged $15-24$ years; $8.80 \%$ were $25-34$ years; $28.40 \%$ were 55-64 years; and $13.10 \%$ were 65 years and older. Place of injury was largely unspecified; four categories (farm, recreation/ sport, street/highway, public building) —each averaging under $2.5 \%$-were included within other/unspecified. Descriptive characteristics were broken out by state where counts sufficed, with some age and race/ethnicity categories collapsed (table 3 ).
State-based 5-year average annual crude rates of prescription opioid overdose/AE hospitalisations among injured workers ranged from 0.3 to 1.2 events per 100000 employed workers (table 4). Among inpatients ages 15-64 years (age range restricted to enhance comparability across groups), rates for injured workers ranged from 0.3 to 1.1 events per 100000 employed workers, while rates for all inpatients ranged from 39.6 to 78.2 events per 100000 civilian population.

Five-year average annual age and gender-specific rates of prescription opioid overdose/AE hospitalisations among injured

Table 3 Worker and event characteristics (percentages) among injured workers with prescription opioid overdose or adverse effect hospitalisations by state (2010-2014)

\begin{tabular}{|c|c|c|c|c|c|c|c|c|c|}
\hline Characteristic & $\begin{array}{l}A Z \\
(n=133)\end{array}$ & $\begin{array}{l}\mathrm{CO} \\
(n=110)\end{array}$ & $\begin{array}{l}\mathrm{MI} \\
(\mathrm{n}=83)\end{array}$ & $\begin{array}{l}\text { NJ } \\
(n=85)\end{array}$ & $\begin{array}{l}N Y \\
(n=340)\end{array}$ & $\begin{array}{l}S C \\
(n=31)\end{array}$ & $\begin{array}{l}\text { UT } \\
(n=32)\end{array}$ & $\begin{array}{l}\text { WA } \\
(n=186)\end{array}$ & $\begin{array}{l}8 \text { states* } \\
(n=1000)\end{array}$ \\
\hline \multicolumn{10}{|l|}{ Gender } \\
\hline Men & 61.65 & 66.36 & 55.42 & 63.53 & 53.24 & NR & NR & 63.98 & 60.10 \\
\hline Women & 38.35 & 33.64 & 44.58 & 36.47 & 46.76 & NR & NR & 36.02 & 39.90 \\
\hline \multicolumn{10}{|l|}{ Age (years) } \\
\hline 15-34 & 13.53 & 16.36 & 21.69 & NR & 10.00 & NR & NR & 6.45 & 11.50 \\
\hline $35-44$ & 13.53 & 12.73 & 20.48 & NR & 21.47 & NR & NR & 20.43 & 18.90 \\
\hline $45-54$ & 21.05 & 31.82 & 25.30 & 40.00 & 30.00 & NR & NR & 22.04 & 28.10 \\
\hline $55+$ & 51.88 & 39.09 & 32.53 & 27.06 & 38.53 & 35.48 & 50.00 & 51.08 & 41.50 \\
\hline \multicolumn{10}{|l|}{ Race/ethnicity } \\
\hline Non-Latino white & 76.69 & 66.67 & 92.31 & 65.06 & 78.82 & 87.10 & 79.17 & 90.18 & 79.21 \\
\hline Latino/Hispanic & NR & 18.18 & NR & 16.87 & 7.94 & NR & NR & NR & 9.91 \\
\hline Other/multiple & NR & 15.15 & NR & 18.07 & 13.24 & NR & NR & NR & 10.87 \\
\hline \multicolumn{10}{|l|}{ Place of injury } \\
\hline Home & 9.77 & 14.55 & NR & NR & 8.24 & NR & NR & NR & 8.80 \\
\hline Industrial/mine/quarry & 22.56 & 10.00 & NR & NR & 5.29 & NR & NR & NR & 7.80 \\
\hline Residential institution† & 17.29 & 24.55 & 19.28 & NR & 6.47 & NR & NR & 11.29 & 13.00 \\
\hline Other/unspecified & 50.38 & 50.91 & 62.65 & 80.00 & 80.00 & 74.19 & 53.13 & 80.11 & 70.40 \\
\hline Low back disorder & 18.80 & 29.09 & 25.30 & 37.65 & 35.59 & NR & NR & 25.81 & 28.60 \\
\hline
\end{tabular}

*Percentages in the eight-states column were averaged across all eight states and included cells not separately reported.

tResidential institution category includes hospitals, nursing homes, assisted living, jail and prison. Event could have occurred while a resident, at work or visiting

AZ, Arizona; CO, Colorado; HCUP, Healthcare Cost and Utilization Project; MI, Michigan; NJ, New Jersey; NR, not reported due to small cell size ( $\leq 10$ ), in accordance with HCUP guidance; NY, New York; SC, South Carolina; UT, Utah; WA, Washington. 
Table 4 Five-year average annual crude rates* of prescription opioid overdose or adverse effect hospitalisations among injured workers (per 100 000 employed workers) and among all inpatients (per 100000 civilian population) by state (2010-2014)

\begin{tabular}{|c|c|c|c|c|c|c|c|c|}
\hline & $A Z$ & $\mathrm{CO}$ & MI & NJ & NY & SC & UT & WA \\
\hline & Rate (n) & Rate (n) & Rate (n) & Rate (n) & Rate (n) & Rate (n) & Rate (n) & Rate (n) \\
\hline & $(\mathrm{Cl}+)$ & $(\mathrm{Cl}+\mathrm{t})$ & $(\mathrm{Cl}+)$ & $(\mathrm{Cl}+)$ & $(\mathrm{Cl}+)$ & $(\mathrm{Cl}+)$ & $(\mathrm{Cl}+)$ & $(\mathrm{Clt})$ \\
\hline Injured workers & 0.94 (133) & $0.86(110)$ & $0.39(83)$ & $0.41(85)$ & $0.77(340)$ & $0.31(31)$ & $0.49(32)$ & $1.16(186)$ \\
\hline Age $15+$ years & (0.79 to 1.12 ) & (0.71 to 1.03 ) & (0.31 to 0.48 ) & (0.33 to 0.51$)$ & (0.69 to 0.86 ) & (0.21 to 0.44 ) & (0.33 to 0.69 ) & (1.00 to 1.34 ) \\
\hline Injured workers & $0.77(104)$ & $0.81(99)$ & $0.38(77)$ & $0.39(76)$ & $0.71(296)$ & $0.31(29)$ & $0.44(28)$ & $1.05(160)$ \\
\hline Ages $15-64$ years & (0.63 to 0.94 ) & (0.66 to 0.98 ) & (0.30 to 0.47 ) & (0.31 to 0.49 ) & (0.63 to 0.79 ) & (0.21 to 0.44 ) & (0.29 to 0.64$)$ & (0.89 to 1.22 ) \\
\hline All inpatients & 78.2 (16 505) & 61.8 (10 851) & $63.6(20$ 960) & 39.6 (11 689) & $40.5(26820)$ & $47.3(7294)$ & $60.6(5523)$ & 60.4 (13 945) \\
\hline Ages $15-64$ years & (77.0 to 79.4 ) & (60.6 to 62.9 ) & (62.8 to 64.5 ) & (38.8 to 40.3 ) & (40.0 to 41.0$)$ & (46.2 to 48.4 ) & (59.0 to 62.2 ) & (59.4 to 61.4 ) \\
\hline
\end{tabular}

*Employed worker denominators were used to calculate injured worker rates and were based on the Bureau of Labour Statistics' Current Population Survey. Civilian population denominators were used to calculate rates for all inpatients and were based on US Census Bureau annual estimates.

tPoisson exact $95 \%$ confidence intervals.

AZ, Arizona; CO, Colorado; MI, Michigan; NJ, New Jersey; NY, New York; SC, South Carolina; UT, Utah; WA, Washington.

workers were reported for six states (table 5). In each state, the estimated rate for men was higher than that for women. In the four states with estimated rates for every age category, there was a monotonic increase with age. Rates for injured workers ages 65 years and older ranged from 1.9 to 4.4 per 100000 employed workers.

\section{DISCUSSION}

Five-year average annual crude rates of prescription opioid overdose/AE hospitalisations among injured workers varied by state but were in the general neighbourhood of 1 event per 100000 employed workers. Among those hospitalised with prescription opioid overdose/AE, injured workers were more likely than other inpatients to have a low back disorder diagnosis and were less likely to have a diagnosis of opioid dependence/abuse or cancer, or to have a fatal outcome. In each state, the estimated rate for men was higher than that for women, though the difference was quite small in some states. Several studies indicate that men are at higher risk than women for escalation to high-dose opioid therapy and opioid-related mortality. ${ }^{30-32}$

Findings by age were particularly notable. Averaged across eight states, $28 \%$ of injured workers with prescription opioid overdose/AE hospitalisations were aged 55-64 years, and 13\% were 65 years and older. In the four states with estimated rates for every age category, there was a monotonic increase with age, and rates for injured workers ages 65 years and older ranged from two to six times the overall rates. Middle-aged adults have the highest prescription opioid-related mortality rates, ${ }^{31} 32$ but adults aged 65 and older have recently had the largest increases in both opioid-related overdose hospitalisations $^{33}$ and mortality. ${ }^{31} 32$ Prescription opioid-related morbidity may be exacerbated for older workers due to physiological changes associated with ageing, as well as higher prevalence of chronic conditions, complex social needs, mental health issues

Table 5 Five-year average annual gender-specific and age-specific rates* of prescription opioid overdose or adverse effect hospitalisations among injured workers (per 100000 employed workers) by statet (2010-2014)

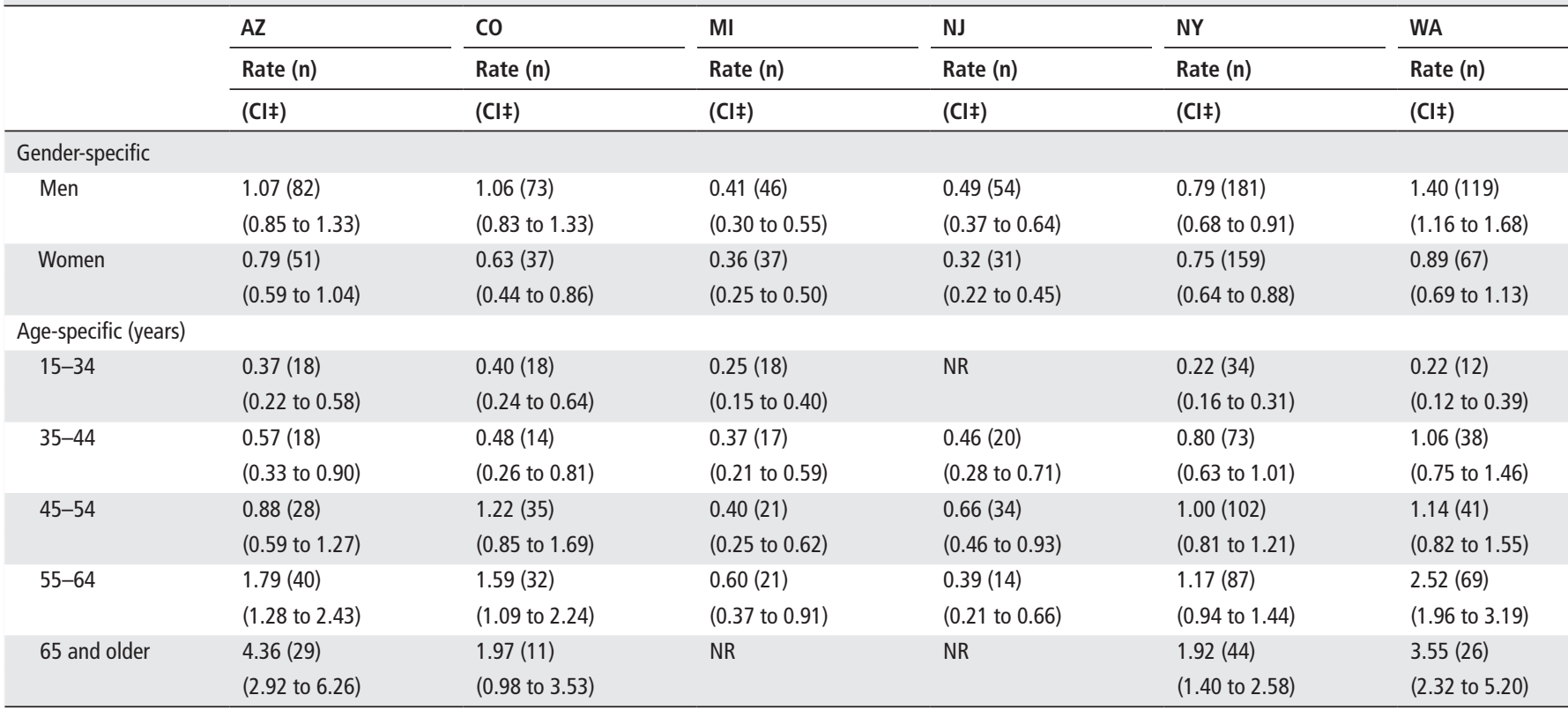

*Employed worker denominators were used to calculate injured worker rates and were based on the Bureau of Labour Statistics' Current Population Survey.

tSouth Carolina and Utah were excluded from table 5 due to small numbers.

¥Poisson exact $95 \% \mathrm{Cls}$.

AZ, Arizona; CO, Colorado; MI, Michigan; NJ, New Jersey; NR, not reported due to small cell size ( $\leq 10)$, in accordance with HCUP guidance; NY, New York; WA, Washington. 
and multiple prescription medications (with potential adverse drug interactions). ${ }^{33}$

Five-year average annual crude rates of prescription opioid overdose/AE hospitalisation rates for all inpatients (ages 15-64 years) ranged from about 40 to 78 events per 100000 civilian population, many times higher than for injured workers. Among all inpatients aged 15-64 years (not restricted to injured workers), WC was the primary expected payer for less than $1 \%$ of prescription opioid overdose/AE hospitalisations, averaged across all eight states. In contrast, WC was listed as the primary expected payer for roughly $6 \%$ of injury hospitalisations and $5 \%$ of hospitalisations with a low back disorder diagnosis, averaged across all eight states (table 1). It could be that WC is not paying for some WC-related overdose/AE events. Alternatively, these events could truly be much rarer among injured workers; however, previous research showing higher opioid doses in WC settings raises the possibility of higher but largely undetected morbidity/mortality rates. ${ }^{8}$ Among injured workers 15 years and older who were identified using only E-codes (online supplementary table 1), WC was the primary expected payer for $67.43 \%$ of hospitalisations for any diagnosis and for $59.42 \%$ when restricted to prescription opioid overdose/AE hospitalisations, averaged across all eight states. These coverage levels are roughly comparable to previous estimates of WC coverage of industrial injury hospitalisations ${ }^{34}$ and suggest that WC may be somewhat less likely to cover opioid morbidity-related hospitalisations compared with injury hospitalisations.

Identification and surveillance of work-related injury/illness in clinical databases often rely on using WC as payer, including the analyses conducted for this study. However, for workrelated injury/illness not covered by WC, consequent prescription opioid overdose/AE would also not be covered and thus obscured from surveillance. Alternative research approaches are needed to assess the degree to which WC as payer identifies work-related opioid morbidity. These could include linking WC claims to other databases containing opioid-related outcomes (eg, emergency medical services, emergency department visits and hospital discharges).

The extent to which work-related prescription opioid morbidity is not covered by WC is unknown. However, an estimated $75 \%$ of the economic burden of work-related injury/illness (including direct healthcare costs and indirect work productivity, lost wages and home production costs) is transferred as an externality from the responsible employers to society more generally (eg, workers and their families, non-WC insurers, healthcare systems, the social safety net and taxpayers). ${ }^{1}{ }^{35}$ Healthcare providers employing high-risk opioid prescribing practices further contribute to this burden.

Many state agencies and WC systems are actively engaged in prevention efforts focused on curbing high-risk opioid prescribing practices. Successful opioid morbidity reduction will also depend on appropriate WC coverage for treatment of opioid use disorders stemming from opioids prescribed after a work injury. Improved surveillance is possible through real-time tracking of opioid overdose/AE, with reports to the prescribing and/or primary care provider, important because most patients surviving these events continue to be prescribed opioids and are at high risk of repeat overdose. ${ }^{36}$

\section{Limitations}

Although our case definition ensured that hospital discharges were limited to injured workers (ie, WC as primary expected payer or work-related E-code), the prescription opioid morbidity we identified could involve several different workrelated scenarios, as described earlier. Caution is needed when comparing rates across states or across years within states, due to variation in factors such as penetration of WC coverage, coverage rules, counts of E-code and diagnosis fields, usage of specific E-codes, the proportion of overdose/AE events that are treated on an inpatient basis. The states included in this study were selected in part due to E-code usage criteria, and findings may not generalise to all states. Further, this study has limited generalisability beyond the USA. As $\mathrm{Ho}^{37}$ comprehensively described, many factors have contributed to the USA being an international outlier in drug overdose mortality since the early 2000s, including (1) wider and more permissively regulated use of opioids for non-cancer pain, (2) reimbursement practices favouring prescription drugs over alternative pain therapies, (3) wider use of benzodiazepines, (4) fragmented healthcare system and (5) scarcity of substance use treatment. Whether the USA is unique provides a cautionary example, or whether it is leading an emerging international trend is not yet known. However, similar trends are emerging in several other developed countries. Despite more limited access to opioids, developing countries have impending risk due to aggressive pharmaceutical marketing, along with weaker regulatory, healthcare and surveillance systems. These factors undoubtedly also affect opioid morbidity/mortality risk for injured workers, but we identified no pertinent international research, indicating an important research gap.

Small numbers presented particular challenges despite our use of a case definition that relied on both work-related E-codes and WC as payer, as well as use of all-listed diagnosis/E-code fields. We were unable to age/sex adjust rates and needed to suppress many counts and estimates to comply with HCUP reporting restrictions. Overdose counts were too low to present rates for overdose and AE separately. The appropriateness of combining these two categories is an unresolved point of discussion in the literature. ${ }^{113839}$ Due to small numbers, we also included all available diagnoses and E-code fields, rather than restricting to the lowest number common to all included states and years. As a counterpoint, many of our metrics were roughly similar across the eight states, showing stability despite the relatively small numbers of events.

This study did not attempt to quantify all opioid-related morbidity. However, hospital discharge data do capture a large share of opioid morbidity. Based on Washington State WC billing data, over $40 \%$ of opioid poisonings and $\mathrm{AE}$ were treated on an inpatient basis, ${ }^{11}$ and a nationally representative study documented that over half of prescription opioid poisonings presenting to an emergency department were admitted to the hospital. $^{40}$

\section{CONCLUSIONS}

Accurate surveillance of opioid morbidity rates and demographic patterns is necessary for effective prevention. In this study, we estimated opioid-related morbidity among injured workers, for whom population-based estimates are almost non-existent. Estimated prescription opioid overdose/AE hospitalisation rates were quite low, roughly 1 per 100000 workers. Rates were highest among male workers and older workers; rates for workers 65 years and older were two to six times the average. Additional research is needed to further characterise the burden of opioid-related morbidity and mortality among injured workers, including the downstream impact of high-risk opioid prescribing practices pursuant to work injury/illness, and to assess the degree 
to which WC as payer adequately identifies work-related opioid morbidity for research and surveillance purposes.

Acknowledgements We acknowledge and thank Rae Wu, Research Consultant with the University of Washington Occupational Epidemiology and Health Outcomes Program, for assistance with data management.

Contributors JMS conceived of and designed the study, was responsible for data management and data analysis, and drafted the initial manuscript. SH-J and DF-K assisted with the study design and statistical methods. RAS assisted with background literature review and constructing population denominators. All authors assisted with the interpretation of the results, edited the manuscript for important intellectual content and approved the final manuscript as submitted.

Funding This work was supported by the National Institute for Occupational Safety and Health (NIOSH, under grant number R03OH010943). Its contents are solely the responsibility of the authors and do not necessarily represent the official views of NIOSH.

Competing interests None declared.

Patient consent for publication Not required.

Ethics approval This study did not involve identifiable human subjects and thus did not require institutional review board approval.

Provenance and peer review Not commissioned; externally peer reviewed.

Data availability statement Data may be obtained from a third party and are not available from the authors. Hospital discharge data are available for purchase directly from the Healthcare Cost and Utilization Project, Agency for Healthcare Research and Quality (https://www.hcup-us.ahrq.gov/databases.jsp).

ORCID iD

Jeanne M Sears http://orcid.org/0000-0002-7325-1279

\section{REFERENCES}

1 Leigh JP. Economic burden of occupational injury and illness in the United States. Milbank O 2011:89:728-72.

2 Park RM, Bhattacharya A. Uncompensated consequences of workplace injuries and illness: long-term disability and early termination. J Safety Res 2013:44:119-24.

3 Dembe AE, Himmelstein JS, Stevens BA, et al. Improving workers' compensation health care. Health Aff 1997;16:253-7.

4 Franklin GM, Wickizer TM, Coe NB, et al. Workers' compensation: poor quality health care and the growing disability problem in the United States. Am J Ind Med 2015:58:245-51.

5 Bohnert ASB, Valenstein M, Bair MJ, et al. Association between opioid prescribing patterns and opioid overdose-related deaths. JAMA 2011:305:1315-21.

6 Centers for Disease Control and Prevention (CDC). CDC grand rounds: prescription drug overdoses - a U.S. epidemic. MMWR Morb Mortal Wkly Rep 2012;61:10-13.

7 Tedesco D, Asch SM, Curtin C, et al. Opioid abuse and poisoning: trends in inpatient and emergency department discharges. Health Aff 2017;36:1748-53.

8 Dembe A, Wickizer T, Sieck C, et al. Opioid use and dosing in the workers' compensation setting. A comparative review and new data from Ohio. Am J Ind Med 2012:55:313-24.

9 Franklin GM, Mai J, Wickizer T, et al. Opioid dosing trends and mortality in Washington state workers' compensation, 1996-2002. Am J Ind Med 2005;48:91-9.

10 Franklin GM, Stover BD, Turner JA, et al. Early opioid prescription and subsequent disability among workers with back injuries: the disability risk identification study cohort. Spine 2008;33:199-204

11 Fulton-Kehoe D, Garg RK, Turner JA, et al. Opioid poisonings and opioid adverse effects in workers in Washington state. Am J Ind Med 2013;56:1452-62.

12 White JA, Tao X, Talreja M, et al. The effect of opioid use on workers' compensation claim cost in the state of Michigan. J Occup Environ Med 2012;54:948-53.

13 Kowalski-McGraw M, Green-McKenzie J, Pandalai SP, et al. Characterizing the interrelationships of prescription opioid and benzodiazepine drugs with worker health and workplace hazards. J Occup Environ Med 2017;59:1114-26.

14 National Safety Council. National employer survey 2019: opioid usage in the workplace, 2019. Available: https://www.nsc.org/Portals/0/Documents/ NewsDocuments/2019/PPW-survey-methodology.pdf?ver=2019-03-18-174024-837 [Accessed 28 Dec 2019].

15 National Safety Council. Prescription pain medications: a fatal cure for injured workers, 2015. Available: http://safety.nsc.org/workerscomp [Accessed 31 Dec 2019].
16 Tiesman HM, Konda S, Cimineri L, et al. Drug overdose deaths at work, 2011-2016. Inj Prev 2019;25:577-80.

17 Hawkins D, Roelofs C, Laing J, et al. Opioid-related overdose deaths by industry and occupation-Massachusetts, 2011-2015. Am J Ind Med 2019;62:815-25.

18 Martin CJ, Jin C, Bertke SJ, et al. Increased overall and cause-specific mortality associated with disability among workers' compensation claimants with low back injuries. Am J Ind Med 2020;63:209-17.

19 Applebaum KM, Asfaw A, O'Leary PK, et al. Suicide and drug-related mortality following occupational injury. Am J Ind Med 2019;62:733-41.

20 HCUP State Inpatient Databases (SID). Healthcare cost and utilization project (HCUP). Rockville, MD: Agency for Healthcare Research and Quality (AHRQ), 2010-2014. www.hcup-us.ahrq.gov/sidoverview.jsp

21 Buck CJ. ICD-9-CM Volumes 1, 2, \& 3 for Hospitals, Professional Edition. St. Louis, MO: Elsevier, 2011.

22 Sears JM, Bowman SM, Hogg-Johnson S. Using injury severity to improve occupationa injury trend estimates. Am J Ind Med 2014;57:928-39.

23 Sears JM, Bowman SM, Rotert M, et al. Improving occupational injury surveillance by using a severity threshold: development of a new occupational health indicator. Inj Prev 2016;22:195-201.

24 Slavova S, Bunn TL, Talbert J. Drug overdose surveillance using hospital discharge data. Public Health Rep 2014;129:437-45

25 Council of State and Territorial Epidemiologists (CSTE). Occupational health indicators: a guide for tracking occupational health conditions and their determinants. April 2019. Council of state and territorial epidemiologists in collaboration with the National Institute for occupational safety and health. Available: https://www.cste.org/ resource/resmgr/ohindicators2/2019_OHI_Guidance_Manual.pdf [Accessed 28 Dec 2019].

26 Sears JM, Bowman SM, Silverstein BA, et al. Identification of work-related injuries in a state trauma registry. J Occup Environ Med 2012;54:356-62.

27 Employed Labor Force (ELF). National Institute for Occupational Safety and Health [database on the Internet]. Available: https://wwwn.cdc.gov/wisards/cps/ [Accessed 30 Oct 2019].

28 U.S. Census Bureau. Annual Estimates of the Civilian Population by Single Year of Age and Sex for the United States and States: April 1, 2010 to July 1, 2018 (SCEST2018-AGESEX-CIV) [database on the Internet]. Available: https://www2.census. gov/programs-surveys/popest/tables/2010-2018/state/asrh/sc-est2018-agesex-civ.csv [Accessed 2 Nov 2019].

29 StataCorp. Stata statistical software: release 15. College Station, TX: StataCorp LLC, 2017

30 Kaplovitch E, Gomes T, Camacho X, et al. Sex differences in dose escalation and overdose death during chronic opioid therapy: a population-based cohort study. PLoS One 2015;10:e0134550.

31 Scholl L, Seth P, Kariisa M, et al. Drug and opioid-involved overdose deaths - United States, 2013-2017. MMWR Morb Mortal Wkly Rep 2019;67:1419-27.

32 Wilson N, Kariisa M, Seth P, et al. Drug and Opioid-Involved Overdose Deaths - United States, 2017-2018. MMWR Morb Mortal Wkly Rep 2020;69:290-7.

33 Weiss $\mathrm{A}$, Heslin K, Barrett M, et al. Opioid-related inpatient stays and emergency department visits among patients aged 65 years and older, 2010 and 2015. HCUP Statistical Brief \#244. Rockville, MD: Agency for Healthcare Research and Quality, 2018. www.hcup-us.ahrq.gov/reports/statbriefs/sb244-Opioid-Inpatient-Stays-EDVisits-Older-Adults.pdf

34 Sears JM, Bowman SM, Blanar L, et al. Industrial injury hospitalizations billed to payers other than workers' compensation: characteristics and trends by state. Health Serv Res 2017:52:763-85.

35 Sears JM, Edmonds AT, Coe NB. Coverage gaps and cost-shifting for workrelated injury and illness: who bears the financial burden? Med Care Res Rev 2019:107755871984572

36 Larochelle MR, Liebschutz JM, Zhang F, et al. Opioid prescribing after nonfatal overdose and association with repeated overdose: a cohort study. Ann Intern Med 2016:164:1-9.

37 Ho JY. The contemporary American drug overdose epidemic in internationa perspective. Popul Dev Rev 2019:45:7-40.

38 Dasgupta Net al. Defining controlled substances overdose: should deaths from substance use disorders and pharmaceutical adverse events be included? J Clin Toxicol 2013;3:1000164.

39 Paulozzi LJ, Warner M, Jones CM. Defining controlled substances overdose: some challenges [letter]. J Clin Toxicol 2013;3:1000175.

40 Tadros A, Layman SM, Davis SM, et al. Emergency visits for prescription opioid poisonings. J Emerg Med 2015;49:871-7. 